\title{
Erratum to: Abstracts of the 4th IFSO-European Chapter Congress - Lausanne /Switzerland
}

The Publisher

Published online: 6 May 2010

(C) Springer Science+Business Media, LLC 2010

Erratum to: OBES SURG

DOI 10.1007/s11695-010-0117-z

In Abstract OC37 of the original publication, the order of authors is reversed. The correct authorship is as follows:

Carlos Carrasquilla; Jennifer Gianos; Fernando BayronVelez; Paul Esposito

The online version of the original article can be found at http://dx.doi. org/10.1007/s11695-010-0117-z

The Publisher $(\bowtie)$

233 Spring Street,

New York, NY 10013, USA

e-mail: SpringerAlerts@springeronline.com 